\title{
CORRECTION
}

View Article Online

View Journal I View Issue

Check for updates

Cite this: Phys. Chem. Chem. Phys., 2019, 21, 12704

DOI: $10.1039 / c 9 c p 90142 f$

rsc.li/pccp

\section{Correction: Maxwell-Stefan diffusion coefficient estimation for ternary systems: an ideal ternary alcohol system}

\author{
Tariq Allie-Ebrahim, Qingyu Zhu, Pierre Bräuer, Geoff D. Moggridge and \\ Carmine D'Agostino* $\dagger$
}

Correction for 'Maxwell-Stefan diffusion coefficient estimation for ternary systems: an ideal ternary alcohol system' by Tariq Allie-Ebrahim et al., Phys. Chem. Chem. Phys., 2017, 19, 16071-16077.

There was a typographical error in the originally published manuscript. The error originates in Table 1, the values in which were used to calculate Table 2. The values given in the originally published version of Table 1 cannot be used to satisfactorily fit the VLE data given in the references; and indeed cannot be used to obtain the values which were published in Table 2. Following re-calculation of the binary NRTL parameters, obtained by a least squares fit to the binary VLE data sets, a revised Table 1 is given below.

From this revised Table 1, a new Table 2 (shown below) was also calculated. The values in the revised Table 2 are very similar to those in the original Table 2, and therefore the key conclusion that all mixtures are very close to ideal holds. Thus, the discussion and conclusions of the paper remain unaltered.

Table 1 Regressed ternary NRTL parameters for methanol (1)/butan-1-ol (2)/propan-1-ol (3) at $298 \mathrm{~K}$

\begin{tabular}{llll}
$i-j$ & $\tau_{i-j}$ & $\tau_{j-i}$ & $\alpha$ \\
\hline $1-2$ & 1.0814 & -0.7105 & 0.3 \\
$1-3$ & 1.1651 & -0.8166 & 0.3 \\
$2-3$ & 0.0491 & -0.0138 & 0.3
\end{tabular}


Table 2 Calculated thermodynamic correction factor matrix, $\Gamma$, for methanol (1)/butan-1-ol (2)/propan-1-ol (3) using the regressed ternary NRTL parameters for the eight mixtures investigated

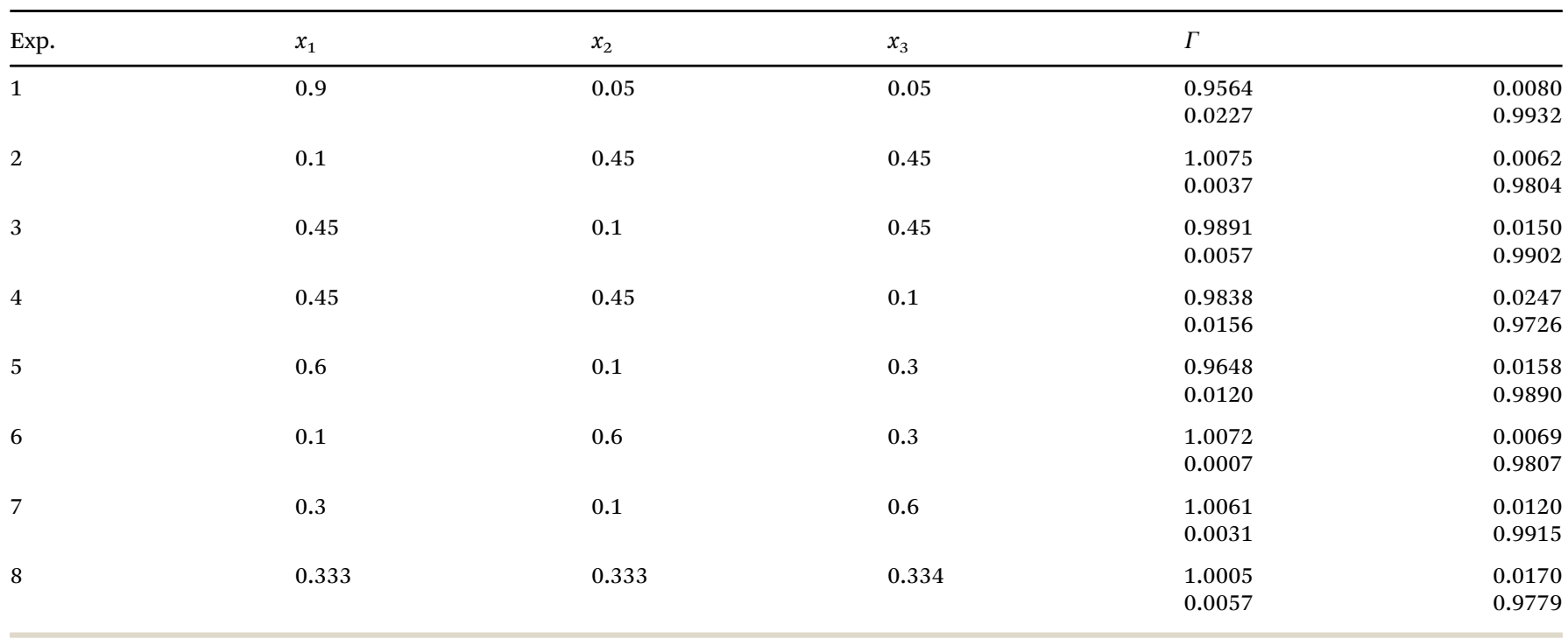

The Royal Society of Chemistry apologises for these errors and any consequent inconvenience to authors and readers. 